\title{
Microtia with meatal atresia and conductive deafness: mild and severe manifestations within the same sibship
}

\author{
P STRISCIUGLiO, A BALLABIO, AND G PARENTI \\ From the Department of Pediatrics, 2nd Medical School, University of Naples, Italy.
}

SUMMARY Hereditary malformations of the external ear, such as microtia and meatal atresia, not associated with other congenital defects or syndromes, are rarely reported. Only a few familial cases have been described in which both dominant and recessive inheritance has been suggested. We report a sibship in which a wide variation of expression is present and recessive inheritance can be postulated.

\section{Case reports}

\section{CASE 1}

Case 1 was an 8 month old male, born at term to a G4, P3, Abl, 26 year old woman, after an uncomplicated pregnancy. There was no exposure to any known teratogenic agent during pregnancy. Delivery was uncomplicated and spontaneous and his birth weight was $3650 \mathrm{~g}$. The parents were healthy and non-consanguineous. There was no family history of ear abnormalities, hearing loss, or other congenital malformations (fig 1). On admission at 8 months of age, physical examination showed an infant with unilateral right microtia, bilateral meatal atresia, and a skin appendage on the left cheek (fig 2 ). The eyes, kidneys, and heart were normal, and there were no other abnormalities. Audiometric tests showed a hearing loss of $60 \mathrm{~dB}$ by air

Received for publication 4 April 1985.

Revised version accepted for publication 24 September 1985.

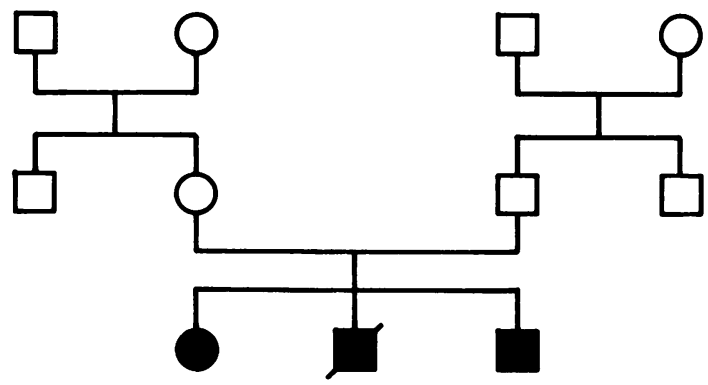

FIG 1 Pedigree shows the absence of ear abnormalities or hearing loss in the relatives of the patients.

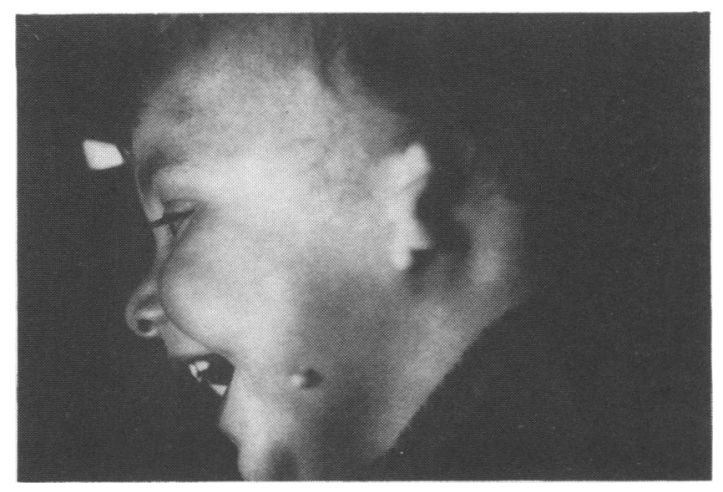

FIG 2 Right microtia and meatal atresia in case 1.

conduction, but no nerve deafness was found. However, skeletal $x$-rays showed absence of hemivertebrae or hypoplastic vertebrae. Growth and psychomotor development were normal.

CASE 2

During our investigation of the proband, the family history revealed that his older brother, who died at 8 months of bronchopneumonia, presented with similar manifestations, including unilateral right microtia and ipsilateral meatal atresia (fig 3). No audiometric tests were performed. No other anomalies were reported.

\section{CASE 3}

The proband's older sister, aged 7 years, had a preauricular left appendage with absence of other anomalies (fig 4). Audiometric tests were normal. 


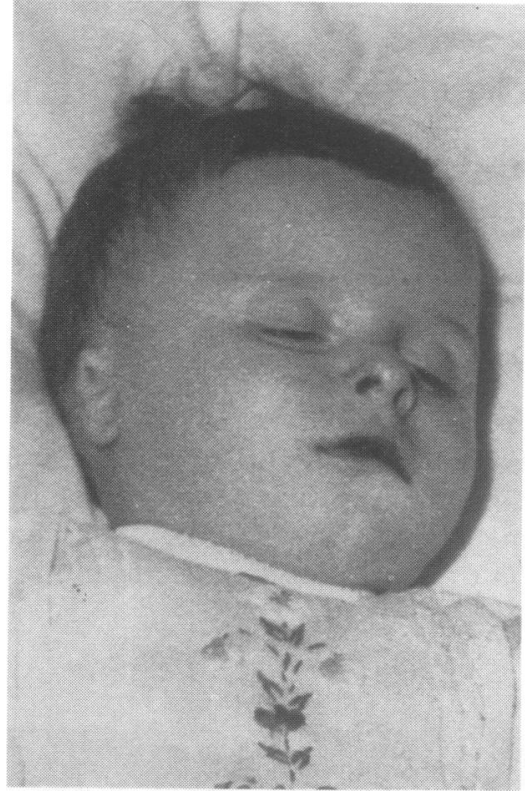

FIG 3 Right microtia and meatal atresia in the dead brother of the proband.

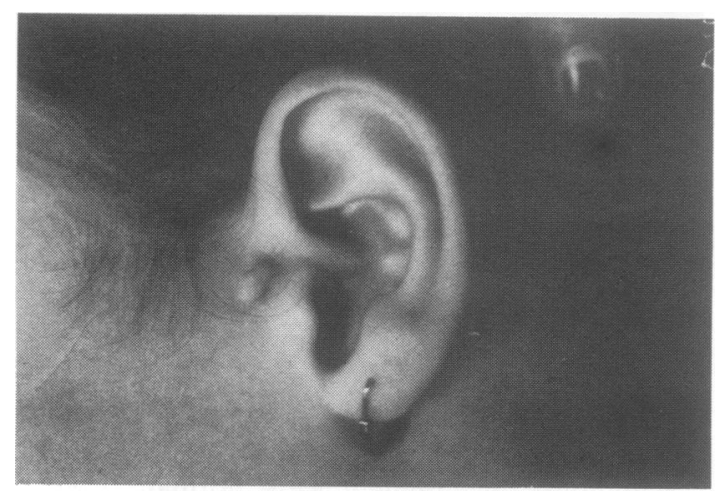

FIG 4 Left preauricular appendage in case 3.

\section{Discussion}

A syndrome including unilateral or bilateral microtia, external auditory meatal atresia, and hearing loss was described in two sibships by Ellwood et al and by Dar and Winter. ${ }^{2}$ These authors assumed recessive inheritance, since the parents in one of the families were consanguineous. Konigsmark et $a l^{3}$ also reported a family in which two brothers had auricular atresia and absent pinnae. Both parents were phenotypically normal and there was no family history of ear malformations or hearing loss. In 1978, however, two families were described in whom microtia and meatal atresia were transmitted from a parent to a child. ${ }^{45}$ The anomalies present in our patients suggest the diagnosis of the syndrome described previously and the absence of renal hypoplasia and other branchial arch anomalies excludes the diagnosis of the branchio-oto-renal (BOR) syndrome. ${ }^{6}$ Moreover, the minimal diagnostic criteria of the first and second branchial arch syndrome in which a familial occurrence is described $^{7}$ are also lacking. Finally, the absence of any ear anomaly or hearing problems in the parents suggests autosomal recessive inheritance. Variable expression of the syndrome has been previously reported. In particular, the combination of unilateral and bilateral meatal atresia has been described. ${ }^{1-3}$ In our sibship the full picture of the syndrome is present in the two brothers, and the presence of the preauricular left appendage with absence of other anomalies or hearing loss in the sister probably represents a mild expression of the same syndrome. Our family, to the best of our knowledge, is the first sibship in which mild and severe manifestations of the syndrome are described. The reason for this clinical variation is unclear. Further reports of families with similar manifestations are required to confirm recessive inheritance in the syndrome and to establish a risk factor for the recurrence of severe malformations of the external ear.

\section{References}

1 Ellwood LC, Winter ST, Dar H. Familial microtia with meatal atresia in two sibships. $J$ Med Genet 1968;5:289-91.

2 Dar H, Winter ST. Letter. J Med Genet 1973;10:305-6.

${ }^{3}$ Konigsmark BW, Nager GT, Haskins HL. Recessive microtia meatal atresia and hearing loss. Arch Otolaryngol 1972;96: 105-9.

4 Jardsoerfer RA. Congenital atresia of the ear. 81st Annual Meeting of the American Laryngological, Rhinological and Otological Society, 1978.

5 Guizar-Vaquez J, Arrendondo-Vega F, Rostenberg I, Manzano C, Armendares S. Microtia and meatal atresia in mother and son. Clin Genet 1978;14:80-2.

6 Smith D. Recognizable patterns of human malformation. Philadelphia: Saunders, 1982:180-1.

${ }^{7}$ Smith D. Recognizable patterns of human malformation. Philadelphia: Saunders, 1982:497-500.

Correspondence and requests for reprints to Dr $\mathrm{P}$ Strisciuglio, Department of Pediatrics, 2nd Medical School, University of Naples, Via S Pansini 5, 80131 Naples, Italy. 